可梘化情報 Vol.15 Suppl. No.1 (1995年7月)

\title{
234 斜航する船体の船尾流場計測
}

船舶技術研究所二村 正○野中 晃二原口富博上野道雄

\section{Measurement of Stern Flow Field around Ships in Oblique Towing Motion}

Tadashi NIMURA*, Koji NONAKA*, Tomihiro HARAGUCHI", Michio UENO*

In this paper, we describe on the results of our investigation of a stern flow field around a ship in oblique towing motion. The purpose of this inveitigation is to get basic data available for developing, improving and verifying an estimation method of hydrodynamic forces acting on a ship in manoeuving motion. Kinds of experiments which we carried out on three VLCC model ships are measurements of flow field by 5 hole Pitot tube, observation of flow field by tuft and measurements of hydrodynamic forces acting on a model ship. By these experiments, we investigated characteristics of flow field around a ship in oblique towing motion, and discussed relation between stern shape, flow field and hydrodynamic forces.

\section{1.はじめに}

現在、船舶の操縦性能を推定する場合、船体に関しては船の長さや幅等の主要な寸法比 から推定しているが、主要寸法は同じでも船尾の形状が違うと操释性能が大きく変化する 例が報告されている。ところで、船体に㗢く操縦流 体力を推定するためには、横力発生の主要因となる 剥離渦を含む船尾付近の流場の把握が特に重要であ る。そこで、斜航する船体の船尾形状と船尾流場、 流体力との関保の把握、操絴流体力推定法開発のた めの資料収集を目的として、主要寸法が同じで船尾

Table 1 Principal Particulars of Models 形状のみが異なる 3 隻のタンカー船型について、蛍光タフト グリッド法による船尾流場の可視化、5孔ピト一管による船 尾流場の計測、流体力計測等を行った。本論では、蛍光タフ トグリッド法による船尾流場の可視化結果をビデオで紹介す ると共に、船尾形状の違いによる船尾流場や流体力への影響 について報告する。

\section{2. 供試模型船及び寒験内容}

供試模型船の主要寸法をTable 1に、船体形状をFig.1に 示す。上から船尾の断面形状が V型、中間型、U型の船型で ある。実験は电航水槽で船体単独について行った。本論で述 へる実験内容をTable 2 に示す。流場計測は直径 $12 \mathrm{~mm}$ の球

\begin{tabular}{|c|c|c|c|}
\hline & V Shape & $\begin{array}{c}\text { Medium } \\
\text { Shape }\end{array}$ & U Shape \\
\hline $\begin{array}{c}\text { Length (m) } \\
\text { Breadth (m) }\end{array}$ & 0.530 & 3.50 & 3.50 \\
Draft (m) & 0.211 & 0.634 & 0.634 \\
Disp. ([ $\left.{ }^{3}\right)$ & 0.3770 & 0.211 & 0.211 \\
\hline
\end{tabular}

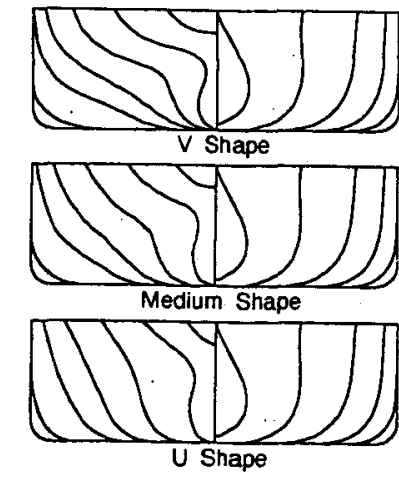

Fig.1 Body Plans

* Ship Reseach Institute, 6-38-1 Sinkawa Mitaka Tokyo 181 Japan. 
形 5 孔と゚トー管を使用し、Fig.2 に示すように电引車の進行方向に垂直な断面を、上下左 右とも $20 \mathrm{~mm}$ 間隔で計測を行っだ。計測結果は 5 秒間の圧力の平均値から求めた流場であ る。計測断面は船体のA.P. (舵軸) 位置である。流場観測は䖝光タフトグリッド法により 行った。最近タフト法の新しい手法として、航空機や自動車分野で蛍光ミニタフト法が用 いられているが、通常のタフト法に比べ鮮明な画像が得られている4)。そこで、水中にも この方法の適用を試みた。グリッド部の寸法は幅 $400 \mathrm{~mm}$ 、深さ $240 \mathrm{~mm} 、 20 \mathrm{~mm}$ 間隔の格子 である。タフトは、水中での紫外線の滅衰が大きいことを考慮して、太さ $0.8 \mathrm{~mm}$ 、長さ $50 \mathrm{~mm}$ 爯光染料で染色したナイロン製を使用した。比重は永よりも僅かに重い。観祭は タフトダリッドの後方に置いた水中ビデオカメラにより行った。照明は水銀灯の外球に柴 外線透過フィルターを使用した市販品で、400W 2 燈を水中に設置した。なお観察断面は 船体があるためA.P.断面よりも140 mm後方の断面を観察している。流体力は船体固定座標 で計測した。

\section{3. 計測結果}

\section{1 蛍光タフトグリッド法による流場観察}

今回行った蛍光タフトグリッド法と蛍光ミニタフト法との主な相違点は、柴外線の減衰 を考虑してタフトをかなり太めにしたことである。しかし、可視化画像から見ると今回使 用したタフトよりもかなり細いタフトでも十分な光量が得られると考えられ、水槽での可 視化法として十分適用可能である と思われる。可視化実験のビデオ 観察によれば、直進状態では左右 対称な船尾縦渦が見られ、斜航角 の增加と共に左舷側の船尾縦渦が 弱くなり、右船側の紸渦及び船体 前半部から発生した渦が强くなっ ていく様子が把握できる。また、 どの状態においてもかなり周期の

Table 2 Experimental Conditions

\begin{tabular}{|c|c|c|c|}
\hline Kind of Experiment & $\begin{array}{c}\text { Wake Measurement } \\
\text { A.P. }\end{array}$ & $\begin{array}{c}\text { Flow Visualization } \\
\text { A.P. }\end{array}$ & $\begin{array}{c}\text { Measurement of } \\
\text { Surge Force and } \\
\text { Sway Force and } \\
\text { Yaw Momcnt }\end{array}$ \\
\hline Measurement Apparatus & 5 Hole Pitot Tube & Tuft Grid & Force Gauge \\
\hline Ship Speed & $\begin{array}{c}\mathrm{U}=0.81 \mathrm{~m} / \mathrm{s} \\
(\mathrm{Fn}=0.138)\end{array}$ & $\begin{array}{c}\mathrm{U}=0.43 \mathrm{~m} / \mathrm{s} \\
(\mathrm{Fn}=0.073)\end{array}$ & $\begin{array}{c}\mathrm{U}=0.81 \mathrm{~m} / \mathrm{s} \\
\mathrm{U}=0.43 \mathrm{~m} / \mathrm{s}\end{array}$ \\
\hline V Sh ape & $\beta=0^{\circ}, 9^{\circ} .18^{\circ}$ & & $\beta=-24^{\circ} \sim+24^{\circ}$ \\
\hline Medi um Shape & $\beta=0^{\circ}, \theta^{\circ}, 18^{\circ}$ & $\beta=0^{\circ}, 45^{\circ} .9^{\circ}, 13.5^{\circ}, 18^{\circ}$ & $\beta=24^{\circ} \sim+24^{\circ}$ \\
\hline U Shape & $\beta=0^{\circ}, 9^{\circ}, 18^{\circ}$ & & $\beta=24^{\circ} \sim+24^{\circ}$ \\
\hline
\end{tabular}

短い流場のゆらきが観察される。このため後述する 5 孔管による流 場計測では流場の細部構造までは計測できていないと考えられるが、 ゆらぎの周期が短いことから平均的な流場としては計測できている と思われる。

\subsection{5 孔管による流場計測結果}

Fig. 3 に各船型の直進状態と斜航角 $18^{\circ}$ の伴流分布（X方向速度 u）/（前進方向速度U）を、Fig. 4 に渦度分布（渦度 $\omega ） \times($ 船 長 L) ノ（前進速度U）を示す。伴流分布についてみると、どちら の状热でも船型の違いが明睹に現れており、U型船型ほど伴流の遅 い部分が広がっている。過度分布では、直進状態についてみると、 U 型船型ほど船尾徉渦が強くなっている。斜航角がついた場合、 $\mathrm{V}$

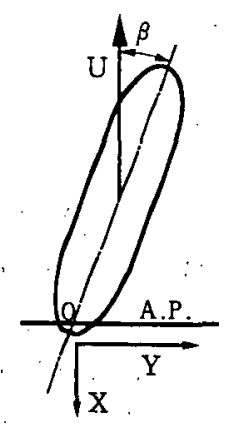

Fig. 2 Cross Sections for Flow Field Measurements 

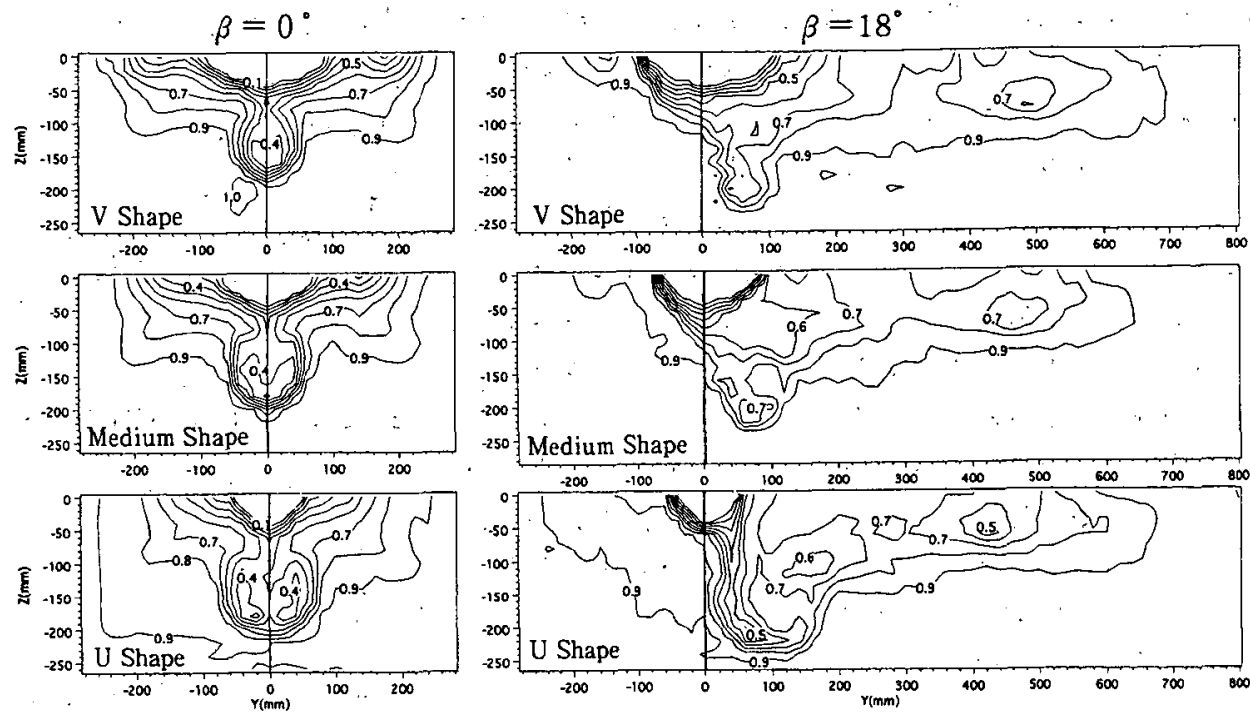

Fig.3 Wake Distribution $\left(\mathbf{u}^{\prime}=\mathbf{u} / \mathrm{U}\right)$
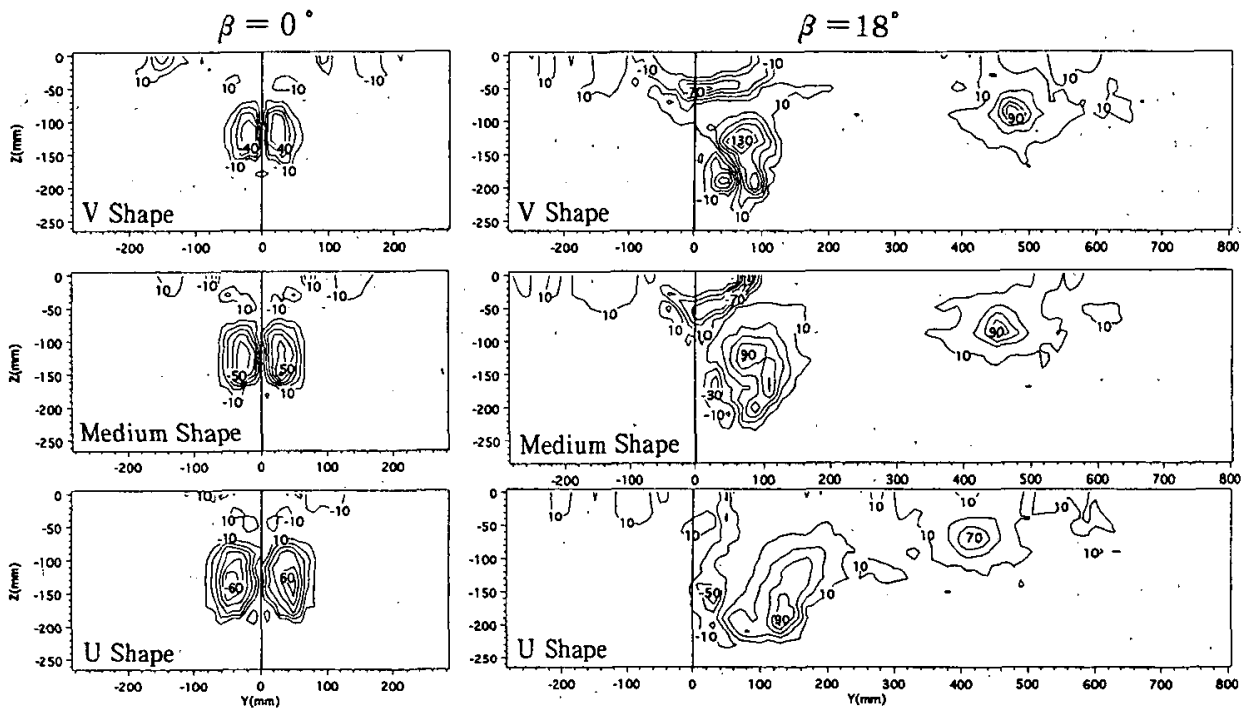

Fig.4 Vorticity Distribution $\left(\omega^{\prime}=\omega \mathrm{L} / \mathrm{U}\right)$

型船型ほど船尾渦、船体前方で発生した渦とも集中度が強い。また、渦の中心位置も船型 によって異なり、計測された船尾流場には、船尾形状の違いが明瞭に現れてる。

\section{3 流体力計測結果}

流体力計測結果として、Fig.5に船体抵抗 X'、Fig. 6 に横力 Y'、Fig.7に回頭モーメン

ト $\mathbf{N}^{\prime}$ 、Fig. 8 にN'/Yで求めた圧力中心 l'を示す。l'=0が船体中心で、0.5が船首である。 
Fig. 6 には 5 孔管流場計測の循環值より求めた横力（ $\mathrm{Y}=$ $\rho \mathrm{U} \Gamma \mathrm{Zo}$ ) を併せて示す。循䍗上り求めた横力は流体力 計測結果と良く一致しており、5孔管による流場計測は 定量的にも精度良く計測されていると考えられる。流体 力の抵抗值に関して見るとV型船型ほど抵抗値は小さく、 推進性能の観点からはV 型船型の方が良い性能であると 言える。この傾向は、V 型船型ほど伴流の荤い面積が小 さかったことと一致している。横力及びモーメントには 船型の違いが余り現れていない。しかし、圧力中心とし て見るとその差がはっきり現れてくる。斜航角が大きい 場合には船型の違いによる差は余りなく、斜航角が小さ くなるに従いV型船型ほど圧力中心が船体前方へ移動し ている。この傾向は、針路安定性上重要となる小さな斜 航角に置いて、V型船型は圧力中心がかなり船体前方に あり、針路不安定になりやすいと考えら机、操稼性能の 観点から考えるとU型船型の方が好ましい性質を持って いると需える。

\section{4.扔わりに}

船体主要目は同じで、船尾の断面形状が異なる、V型、 中間型、U型の 3 船型について流場計測や流体力計測を 行った結果、以下のことが明らかとなった。

1）可視化実験や 5 孔管による流場計測により、斜航船 体の船尾流場の㥞子、船尾形状よる流場の違いが把 握できた。

2）5 孔管による流場計測により、流場計算等と比較で きる精度の良い流場データが得らた。

3 ）船尾形状の違いによる流体力への影響は、圧力中心 位固の変化として顕著に現れる。 参考文献

1）二村 他：斜航船体についての伴流と流体力の測定、 船研講演会、第62回、1993.11

2 ）二村 他：斜航船体の船尾流場計測、 船研講演会、第64回、1994.12

3）野中 他：斜航船体流場と流体力の計測、 西部造船会会報、第72号、1986.8

4) 高木：自動車における流れの可視化、 流れの可梘化、Vol.5 No.19、1985.10

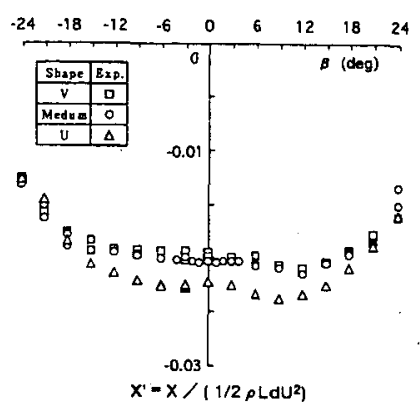

Fig.5 Surge Force $(\mathrm{Fn}=0.138)$

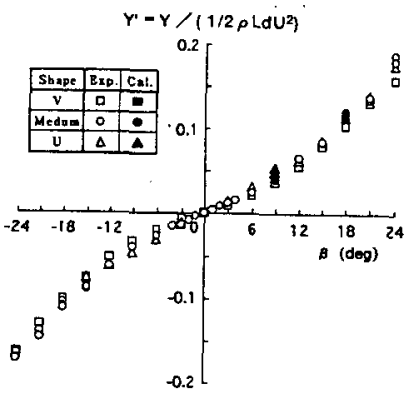

Fig.6 Sway Force $(\mathrm{Fn}=\mathbf{0 . 1 3 8})$



Fig.7 Yaw Moment $(\mathrm{Fn}=0.138)$

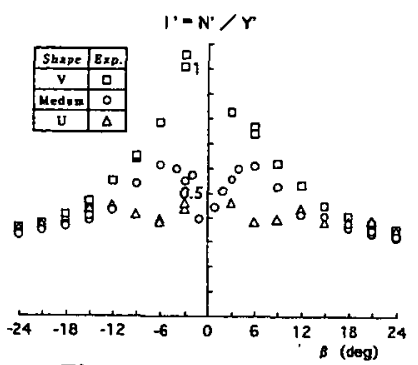

Fig. 8 Center of Pressure

$(\mathrm{F} n=0.138)$ 